\title{
A method of sliding mode control of cart and pole system
}

- Nguyen Van Dong Hai ${ }^{1}$

- Nguyen Minh Tam²

- Mircea Ivanescu ${ }^{1}$

1 University of Craiova, Romania

${ }^{2}$ Ho Chi Minh City University of Technology and Education, Vietnam

(Manuscript Received on July 15, 2015, Manuscript Revised August 30, 2015)

\section{ABSTRACT}

This paper presents a method of using Sliding Mode Control (SMC) for Cart and Pole system. The stability of controller is proved through using Lyapunov function and simulations. A genetic algorithm (GA)

Keywords: Sliding Mode Control, Cart and Pole, Inverted Pendulum, Genetic Algorithm, Matlab/Simulink.

\section{INTRODUCTION}

Cart and Pole system is a popular classical non-linear model used in most laboratories in universities for testing controlling algorithm. Morever, it is a SIMO system in which just one input control must stabilize two outputs: position of cart and angle of pendulum. Many control algorithms were proved to work well on this model [1].

Beside other kinds of control, the nonlinear control, especially Sliding Mode Control (SMC), depends on nonlinear structure of system. So, the stability of system is ensured. Cesar Aguilar [2] set new variable including both Cart's position and Pendulum's angle, neglecting some components in calculating and trying to transform dynamic equation to appropriate form. But it just operated well when the neglected component was not remarkable. Reference [3] introduced other program is used to optimize controlling parameters. The GA-based parameters prove good-quality of control through Matlab/Simulink Simulation. way to set sliding mode for a similar model, the Rotary Inverted Pendulum but did not prove the stability by mathematical methods. Reference [4] and [5] respectively introduced integral SMC and hierarchial SMC applied for Cart and Pole system. But [4] did not prove stability by mathematics or examples in Matlab/Simulink.

This paper presents a new and simple SMC for Cart and Pole system. First, different sliding surfaces are presented. Then, a positive Lyapunov function is set to include both sliding surfaces. A nonlinear way is set to make this function to zero when operating system. After proving stability of controller, GA program is used to optimize controlling parameters.

\section{CART AND POLE SYSTEM}


The studied system in Fig. 1 is a cart of which a rigid pole is hinged. The cart is free to move within the bounds of a one-dimensional track. The pole can move in the vertical plane parallel to the track. The controller can apply a force to the cart parallel to the track.

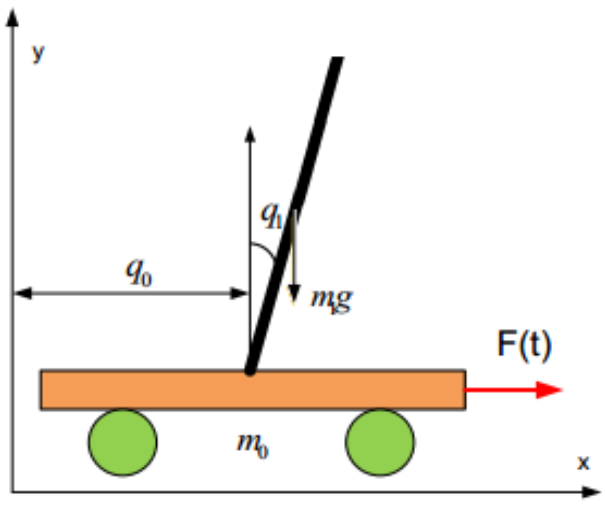

Figure 1: Cart and Pole system

Lagragian equations are:

$\frac{d}{d t}\left(\frac{\partial L}{\partial \dot{q}}\right)-\frac{\partial L}{\partial q}=Q_{p}$

with vector of state variables $q=\left[\begin{array}{l}q_{0} \\ q_{1}\end{array}\right]$

Solve (5) and (6), system dynamic equations are:

$\left\{\begin{array}{c}\left(m_{0}+m_{1}\right) \ddot{q}_{0}+m_{1} l_{1}\left(\ddot{q}_{1} \cos q_{1}-\dot{q}_{1} \sin q_{1}\right)=F-b_{0} \dot{q}_{0} \\ J_{1} \ddot{q}_{1}+m_{1} l_{1}^{2}\left(\ddot{q}_{1} \cos ^{2} q_{1}-2 \dot{q}_{1}^{2} \sin q_{1} \cos q_{1}\right)+m_{1} l_{1}\left(\ddot{q}_{0} \cos q_{1}-\dot{q}_{0} \dot{q}_{1} \sin q_{1}\right)+m_{1} \dot{q}_{1}^{2} l_{1}^{2} \cos q_{1} \sin q_{1}+ \\ +m_{1} \dot{q}_{0} \dot{q}_{1} l_{1} \sin q_{1}-m_{1} g l_{1} \sin q_{1}=-b_{1} \dot{q}_{1}\end{array}\right.$

We can transfrom (7) to the form:

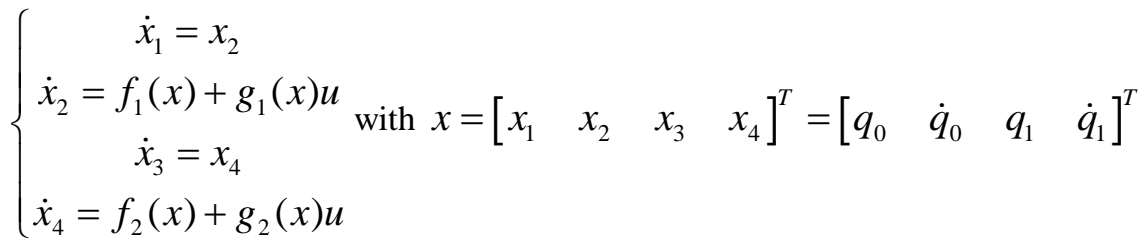

And $f_{1}(x), f_{2}(x), g_{1}(x), g_{2}(x)$ defined as below:

$f_{1}(x)=\frac{\left[\begin{array}{l}-J_{1} b_{0} x_{2}-g l_{1}^{2} m_{1}^{2} \cos x_{1} \sin x_{1}+l_{1}^{3} m_{1}^{2} x_{4} \cos ^{2} x_{3} \sin x_{3}-b_{0} l_{1}^{2} m_{1} x_{2} \cos ^{2} x_{3}+ \\ +J_{1} l_{1} m_{1} x_{4} \sin x_{3}+b_{1} l_{1} m_{1} \dot{q}_{1} \cos \left(x_{3}\right)-l_{1}^{3} m_{1}^{2} x_{4}^{2} \cos \left(x_{3}\right) \sin \left(x_{3}\right)\end{array}\right]}{m_{0} m_{1} l_{1}^{2} \cos ^{2}\left(x_{3}\right)+J_{1} m_{0}+J_{1} m_{1}}$

\section{Trang 168}




$$
\begin{gathered}
g_{1}(x)=\frac{J_{1}+l_{1}^{2} m_{1} \cos ^{2} x_{3}}{m_{0} m_{1} l_{1}^{2} \cos ^{2}\left(x_{3}\right)+J_{1} m_{0}+J_{1} m_{1}} \\
f_{2}(x)=\frac{\left[\begin{array}{l}
\left.g l_{1} m_{1}^{2} \sin x_{3}-b_{1} m_{1} x_{4}-b_{1} m_{0} x_{4}-l_{1}^{2} m_{1}^{2} x_{4} \cos x_{3} \sin x_{3}+l_{1}^{2} m_{1}^{2} x_{4}^{2} \cos x_{3} \sin x_{3}+\right] \\
+b_{0} l_{1} m_{1} x_{2} \cos x_{3}+g l_{1} m_{0} m_{1} \sin x_{3}+l_{1}^{2} m_{0} m_{1} x_{4}^{2} \cos x_{3} \sin x_{3}
\end{array}\right.}{m_{0} m_{1} l_{1}^{2} \cos ^{2}\left(x_{3}\right)+J_{1} m_{0}+J_{1} m_{1}} \\
g_{2}(x)=\frac{l_{1} m_{1} \cos x_{3}}{m_{0} m_{1} l_{1}^{2} \cos ^{2}\left(x_{3}\right)+J_{1} m_{0}+J_{1} m_{1}}
\end{gathered}
$$

Parameters of system is used from the real system in [6], but taking away the second link of the doublelinked Inverted Pendulum to have a Single-linked Inverted Pendulum on Cart (Cart and Pole system). Values of parameters are listed in Table 1.

Table 1: Real System parameters

\begin{tabular}{|l|l|l|l|}
\hline Parameter & \multicolumn{1}{|c|}{ Unit } & \multicolumn{1}{|c|}{ Definition } & Value \\
\hline$m_{0}$ & $\mathrm{Kg}$ & Mass of cart & 0.033 \\
\hline$m_{\mathrm{f}}$ & $\mathrm{Kg}$ & Mass of first pendulum & 1.999 \\
\hline$L_{1}$ & $\mathrm{M}$ & Length of first pendulum & 0.2 \\
\hline$l_{1}$ & $\mathrm{M}$ & Distance between center and rotating axis of first pendulum & 0.115 \\
\hline$J_{1}$ & $\mathrm{kgm}$ & Inertial moment of first pendulum & 0.023 \\
\hline$g$ & $\mathrm{~m} / \mathrm{s}^{2}$ & Gravitation acceleration & 9.81 \\
\hline$F$ & $\mathrm{~N}$ & Force controlling cart & \\
\hline$b_{0}$ & $\mathrm{~kg} / \mathrm{s}$ & Viscous Coefficient of Cart & 0.0001 \\
\hline$b_{1}$ & $\mathrm{Nms}$ & Viscous Coefficient of Rotating Axis of first inverted pendulum & 0.0001 \\
\hline
\end{tabular}

\section{SLIDING MODE CONTROL}

Sliding surfaces are chosen as:

$$
\left\{\begin{array}{l}
s_{1}=x_{1}+\lambda_{1} x_{2} \\
s_{2}=x_{3}+\lambda_{2} x_{4}
\end{array} \text { with } \lambda_{1}=\text { const }>0 \text { and } \lambda_{2}=\text { const }>0\right.
$$

Choosing Lyapunov function:

$$
\begin{aligned}
& V=\left|s_{1}\right|+\lambda_{3}\left|s_{2}\right|>0 \\
& \dot{V}=\dot{s}_{1} \operatorname{sgn}\left(s_{1}\right)+\lambda_{3} \dot{s}_{2} \operatorname{sgn}\left(s_{2}\right)=\left(x_{2}+\lambda_{1} \dot{x}_{2}\right) \operatorname{sgn}\left(s_{1}\right)+\lambda_{3}\left(x_{4}+\lambda_{2} \dot{x}_{4}\right) \operatorname{sgn}\left(s_{2}\right) \\
& =\left\{x_{1}+\lambda_{1}\left[f_{1}(x)+g_{1}(x) u\right]\right\} \operatorname{sgn}\left(s_{1}\right)+\left\{x_{3}+\lambda_{2}\left[f_{2}(x)+g_{2}(x) u\right]\right\} \operatorname{sgn}\left(s_{2}\right) \\
& =\alpha(x)+\beta(x) u
\end{aligned}
$$


With $\alpha(x)=\lambda_{1} \operatorname{sgn}\left(s_{1}\right) f_{1}(x)+\lambda_{3} \operatorname{sgn}\left(s_{2}\right) f_{2}(x)+x_{2} \operatorname{sgn}\left(s_{1}\right)+\lambda_{3} x_{4} \operatorname{sgn}\left(s_{2}\right)$

And $\beta(x)=\lambda_{1} \operatorname{sgn}\left(s_{1}\right) g_{1}(x)+\lambda_{3} \operatorname{sgn}\left(s_{2}\right) g_{2}(x)$

Choosing u that makes:

$\dot{V}=-\lambda_{4}<0$

So, we choose $\lambda_{4}=$ const $>0$

From (15) and (18), we have:

$u=\left[\frac{-\lambda_{4}-\alpha(x)}{\beta(x)}\right]$

In (13), two sliding surfaces are presented with $S_{1}$ includes elements of Cart and $S_{2}$ includes elements of Pendulum. When model is balanced, $S_{\text {fand }} S_{2}$ will move to zero. In this case, we try to reduce $S_{1}$ and $S_{2}$ by setting positive function $V$ in (14).

After generating $\dot{V}$ in (12), we choose control signal $u$ that makes $\dot{V}<0$ in (18). Finally, (19) shows the appropriate control signal u. From (14), (18), we have: $V>0$ and $V \dot{V}<0$ . So, $V \stackrel{t \rightarrow \infty}{\longrightarrow} 0$. From (14), we have: $S_{1} \stackrel{\text { So }{ }_{t \rightarrow \infty}}{\longrightarrow} 0$ and $S_{2} \stackrel{\text { t } \rightarrow \infty}{\longrightarrow} 0$.

\section{GENETIC ALGORITHM}

Stability characteristic of the system is proved in Section 3. With a random parameters of controller like chosen in three examples in Section 5 , we have the simulation results are shown in Fig. 4, Fig. 5, Fig. 6.

As in these figures, the cart's position is stable eventhough quality of control is not so good and the Pendulum's angle is not completely stable but it is not unstable. The force on Cart chatters because of using function sign() in controller. So, genetic algorithm (GA) is used here to optimize control parameters.
In this case, GA used is off-line. Parameters for GA program are listed as below:

- Size of population: $\mathrm{N}=20$

- Linear Ranking Selection: $\eta=0.2$

- Decimal coding

- Two-point crossover

- Crossover parameter: 0.8

- Mutation parameter: 0.2

Choose fitness function:

$$
J=\sum_{i=1}^{n}\left[e_{1}(i)\right]^{2}+\sum_{i=1}^{n}\left[e_{2}(i)\right]^{2}
$$

Figure 2: Block diagram of GA program

With $e_{1}=q_{0}, e_{2}=q_{1}$ and $\mathrm{n}$ is number of samples in one time of simulation. If the controller can stabilize system well, function $\mathrm{J}$ will be very small.

In this case, we operate Simulink program of simulating system in $10 \mathrm{~s}$, with sample-time is 0.01 s. So, we have $\mathrm{n}=1001$ sample.

After 94 generation, the result is $\lambda_{1}=5.84$; $\lambda_{2}=0.06 ; \lambda_{3}=7.42 ; \lambda_{4}=9.84$ and the fitness function is $J=0.8677$. 


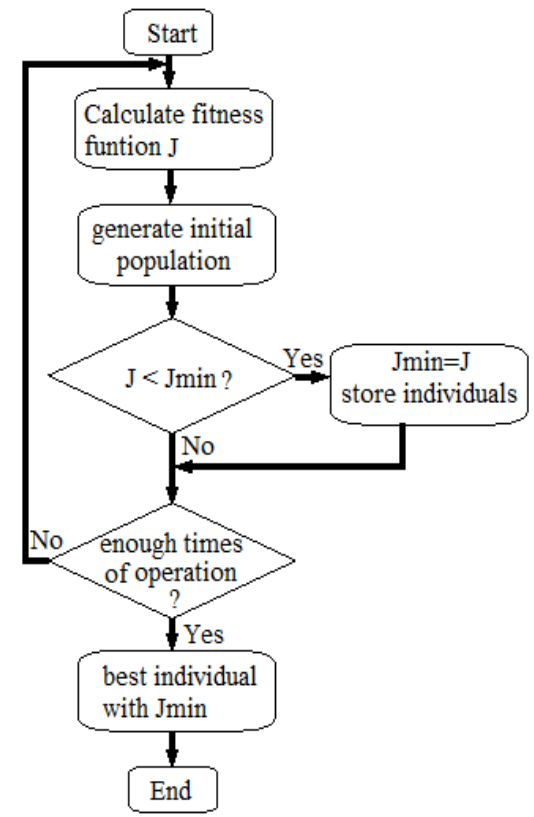

Figure 3: Flow chart of GA Searching process

\section{SIMULATION}

\subsection{Using random controlling parameters}

In order to test the stability of system, we can choose some values of $\lambda_{1} ; \lambda_{2} ; \lambda_{3} ; \lambda_{4}$. Three samples are randomly chosen as:

- Example 1:

$\lambda_{1}=1 ; \lambda_{2}=1 ; \lambda_{3}=1 ; \lambda_{4}=1$

- Example 2:

$\lambda_{1}=10 ; \lambda_{2}=10 ; \lambda_{3}=10 ; \lambda_{4}=10$

- Example 3:

$\lambda_{1}=1 ; \lambda_{2}=2 ; \lambda_{3}=3 ; \lambda_{4}=4$

Choosing initial values of variables are chosen as: $q_{0_{-} \text {init }}=0.1 \quad(\mathrm{~m}), \quad \dot{q}_{0_{-} \text {init }}=-0.1$ $(\mathrm{m} / \mathrm{s}), q_{1_{-} \text {init }}=-0.1(\mathrm{rad}), \dot{q}_{1_{-} \text {init }}=-0.1(\mathrm{rad} / \mathrm{s})$, the simulation results are shown in Fig. 4, Fig. 5, Fig. 6.

In Fig. 4, the cart's position is stable eventhough quality of control is not so good. In Fig. 5, the pendulum's angle is not completely stable but it is not unstable. In Fig. 6, the force on cart chatters because of using function sign() in controller. The SMC algorithm ensures the stability of system but quality is not so good.

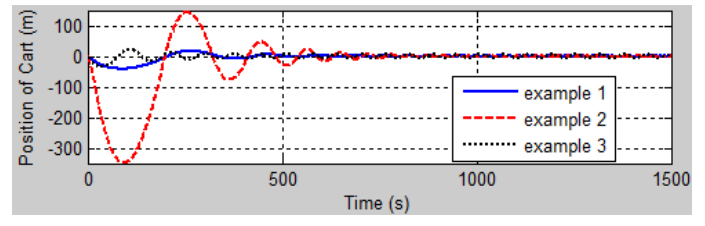

Figure 4: Position of Cart (m) when control parameters are random

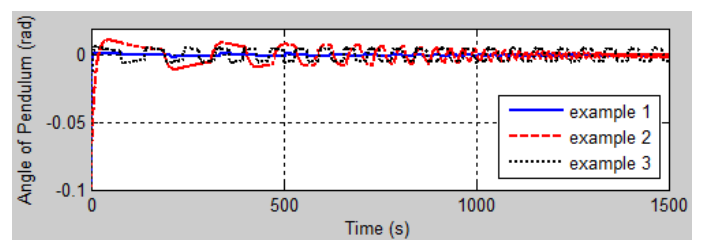

Figure 5: Angle of Pendulum (rad) when control parameters are random

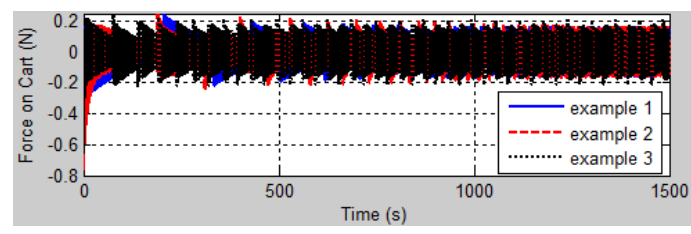

Figure 6: Force on Cart (N) when control parameters are random

\subsection{Using controlling parameters from GA program}

By using GA program in Chapter 4, we have: $\lambda_{1}=5.84, \lambda_{2}=0.06, \lambda_{3}=7.42 ; \lambda_{4}=9.84$.

Choosing initial values of variables are $q_{0_{-} \text {init }}=0.1 \quad(\mathrm{~m}) ; \quad \dot{q}_{0_{-} \text {init }}=-0.1 \quad(\mathrm{~m} / \mathrm{s})$; $q_{1_{-} \text {init }}=-0.1(\mathrm{rad}) ; \dot{q}_{1_{-} \text {init }}=-0.1 \quad(\mathrm{rad} / \mathrm{s})$, and the results of simulation are shown from Fig. 7 to Fig. 13. The cart's position and pendulum's angle move to balancing point after $10 \mathrm{~s}$ and $2.2 \mathrm{~s}$, respectively. In Fig. 9, control signal still chatters but with smaller amplitude than in Fig. 6. Through Fig. 7 to Fig. 8, the variables are proved to stabilized quickly. Fig. 10 and Fig. 11 show the robust characteristics of SMC. Fig. 9 proves the chattering of signal control descreases but not be exterminated. Morever, two sliding surfaces $s_{1}$ and $s_{2}$ are proved to be stabilized quickly in just $3 \mathrm{~s}$ in Fig. 12 and Fig. 13. 


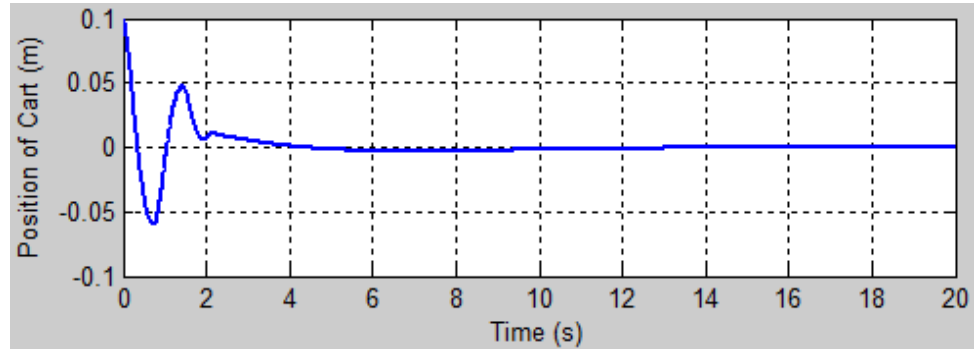

Figure 7: Position of Cart (m) with parameters chosen by GA

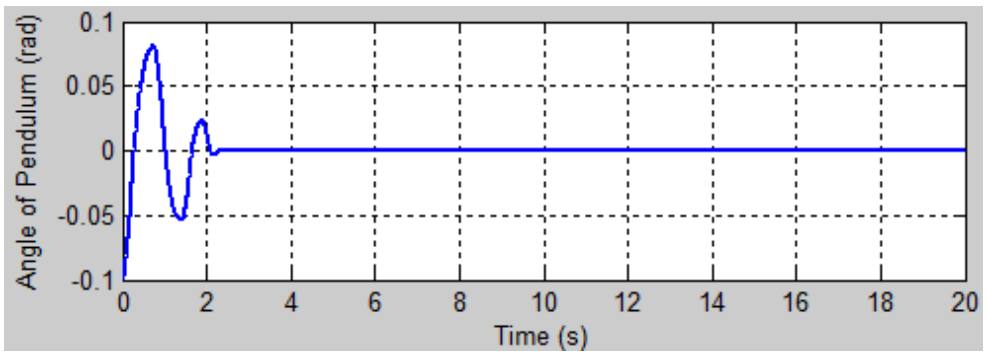

Figure 8: Angle of Pendulum (rad) with parameters chosen by GA

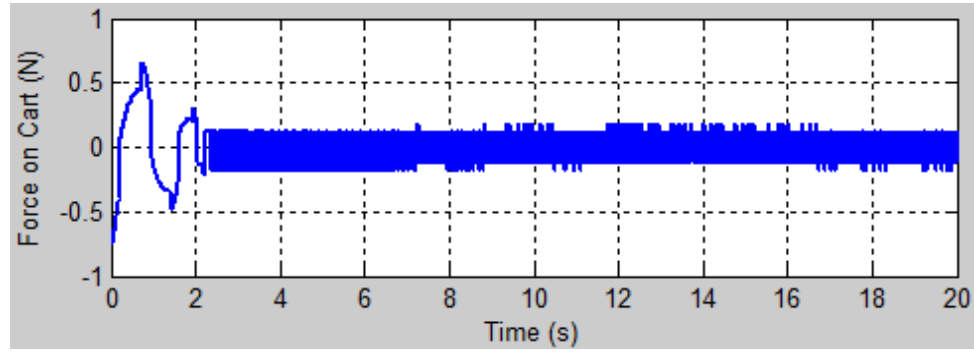

Figure 9: Force on Cart $(\mathrm{N})$ with parameters chosen by GA
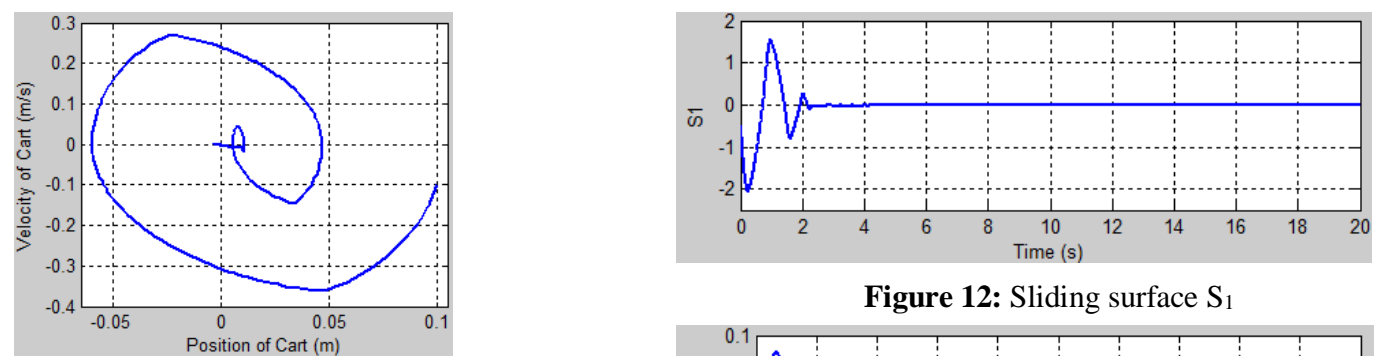

Figure 12: Sliding surface $S_{1}$

Figure 10: Position and Velocity of Cart in 20s
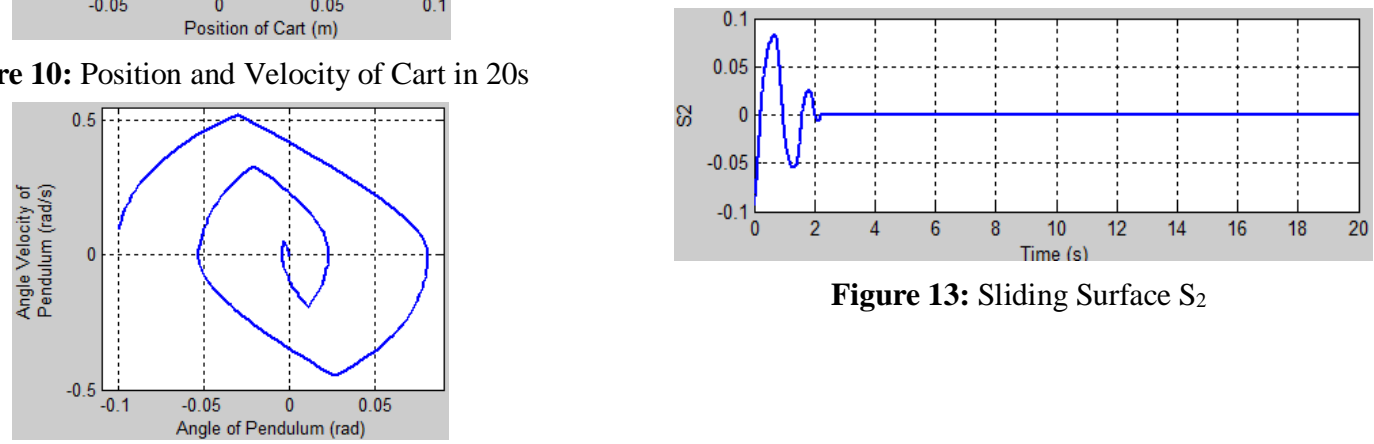

Figure 13: Sliding Surface $S_{2}$

Figure 11: Angle and Angle Velocity of Pendulum in 20s

Trang 172 


\section{CONCLUSION}

This paper presented a new way of SMC to control Cart and Pole system. The stability of controller was proved through Lyapunov setting and random examples. Anyway, the stability of system was ensured but quality of controller was not ensured. To overcome the difference in choosing controlling parameters, one GA program was used to search the optimized controlling parameters. The controller with these parameters worked well in Simulation.

\section{Một phương pháp điều khiển trượt cho hệ con lắc ngược trên xe}

- Nguyễn Văn Đông Hải ${ }^{1}$

- Nguyễn Minh Tâm²

- Mircea Ivanescu ${ }^{1}$

'University of Craiova, Romania

Đại học Sư Phạm Kỹ Thuật Tp. Hồ Chí Minh, Việt Nam

\section{TÓM TÁT}

Bài báo trình bày một phương pháp sử dụng giải thuật điều khiển trượt (SMC) cho hệ con lắc ngược trên xe. Độ ổn định hệ thống của bộ điều khiển được chứng minh thông qua hàm Lyapunov và các kết quả mô phỏng. Một chương trình tính toán áp dụng giải thuật di truyền $(G A)$ được sử dụng để tối ưu hóa các thông số điều khiển.

Từ khóa: Điều khiển trượt, Con lắc ngược trên xe, Giải thuật di truyền, Matlab/Simulink.

\section{REFERENCES}

[1]. Olfar Boubaker, The inverted Pedulum: a fundamental Benchmark in Control Theory and Robotics, pp 1-6, International Conference on Education and e-Learning Innovations (ICEELI), IEEE, (2012).

[2]. Cesar Aguilar, Approximate Feedback Linearization and Sliding Mode Control for the Single Inverted Pendulum, Master Thesis, Queen 's University, England, (2002).

[3]. Mojtaba Ahmadieh Khanesar, Mohammad Teshnehlab, Mahdi Aliyari Shoorehdeli, Sliding Mode Control of Rotary Inverted Pendulum, Proceedings of the $15^{\text {th }}$ Mediterranean Conference on Control \& Automation (IEEE), pp 1-6, Greece, (2007).
[4]. Zhiping Liu, Fan Yu, Zhi Wang, Application of Sliding Mode Control to Design of the Inverted Pendulum Control System, International Conference on Electronic Measurement \& Instrument, ICEMI' 09, Vol. 3, pp 801-805, IEEE, (2009).

[5]. Dianwei Qian, Jianqiang Yi, and Dongbin Zhao, Hierarchical Sliding mode control for a class of SIMO under-actuated systems, Journal of Control and Cybernetics, Vol. 37, No. 1, (2008).

[6]. Tran Vi Do, Nguyen Minh Tam, Ngo Van Thuyen, Nguyen Van Dong Hai, Some methods in controlling Double-linked Inverted Pendulum, National Conference in Mechatronics (VCM), Vietnam, (2014). 